\title{
Implementasi Algoritma Fuzzy Tipe-2 Untuk Penentuan Kriteria Kota Berdasarkan Standar Smart City
}

\author{
M.Nabil Fahd Alfachruddin¹ ${ }^{1}$ Fachrul Kurniawan², Yunifa Miftachul Arif ${ }^{3}$
}

\begin{abstract}
City is a role model which represents the advancement of technology and the existence of prosperity. An improvement of technology should be used as a key to manage city's prosperity. Many standards used to measure the value of city's prosperity. One of that standards is smart city standard. It used factors which define city's prosperity, hence it needs a key factor that allows the standard to produce a crisp result from the available factors. There are 6 key variables of city's prosperity of smart city standard, they are smat governance, smart mobility, smart people, smart economy, smart environment dan smart mobility. Type-2 fuzzy algorithm is used to determine city prosperity' grade using smart city standard. The algorithm is implemented in a game of Malang city's miniature which named after Malang Urban. In this research several in-game experiments are made to get values that meet a specified rules. The values consist $73,33 \%$ of not ready category, $6,67 \%$ of standard category, and $20 \%$ of good smart category of all in-game attempts.
\end{abstract}

Index Terms - general type-2 fuzzy logic system; serious game; smart city.

\begin{abstract}
Abstrak-- Kota adalah tempat yang menjadi tolok ukur kemajuan teknologi dan kesejahteraannya. Teknologi yang berkembang digunakan untuk menopang kesejahteraan kota tersebut. Untuk mengukurnya digunakan standar - standar yang dapat menilai kota tersebut. Salah satu standar penilaian kesejahteraan kota tersebuta adalah smart city. Di dalamnya terdapat faktor - faktor penentu kesejahteraan kota, sehingga dibutuhkan sebuah penentu yang dapat menghasilkan hasil kongkret dari faktor - faktor penentu yang ada. Terdapat 6 variabel penentu kesejahteraan kota dengan standar smart city, yaitu smat governance, smart mobility, smart people, smart economy, smart environment dan smart mobility. Dalam mendapatkan kriteria kesejahteraan kota menggunakan standar smart city digunakan algoritma fuzzy tipe-2 untuk menentukan tingkat kesejahteraan kota. Pada penelitian ini dilakukan penerapan algoritma
\end{abstract}

M. Nabil Fahd Alfachruddin is with the Informatic Engineering Departement of Maulana Malik Ibrahim Islamic State University, Malang, Indonesia (corresponding author provide email civilsociety2011@gmail.com)

Fachrul Kurniawan is with Informatic Engineering Departement of Maulana Malik Ibrahim Islamic State University, Malang, Indonesia.

Yunifa Miftachul Arif is with Informatic Engineering Departement of Maulana Malik Ibrahim Islamic State University, Malang, Indonesia. tersebut dalam bentuk game miniatur kota Malang yang disebut Malang Urban. Dalam penelitian ini dilakukan beberapa percobaan di dalam game untuk mendapatkan nilai yang sesuai dengan kaidah yang telah ditentukan sehingga didapatkan hasil nilai smart city dengan kriteria not ready sebesar $73,33 \%$, standard sebesar $6,67 \%$ dan good smart Sebesar $20 \%$ dari nilai - nilai yang diperoleh dari percobaan di dalam game.

Kata Kunci-general type-2 fuzzy logic system; serious game; smart city.

\section{Pendahuluan}

$\mathrm{K}$ OTA ialah kawasan yang memenuhi berbagai kriteria dalam berbagai aspek. Mayoritas penduduk di area ini bekerja di bidang perdagangan, jasa, dan industri. Sarana di daerah ini terbilang lengkap, dengan adanya fasilitas kesehatan, pendidikan, perdagangan, hiburan, dan lain-lain [1].

Kota merupakan wilayah dalam sebuah negara yang dijadikan perbandingan dalam segi kualitasnya. Oleh karena itu, sebuah kota diharapkan bisa menjadi contoh dalam hal kemajuan teknologi dan kesejahteraan masyarakatnya. Peningkatan kualitas dari kedua hal tersebut dapat membuat sebuah kota mampu untuk terus berkembang dalam segi kualitas.

Tingkat kesejahteraan merupakan tolok ukur dari bagus tidaknya sebuah kota. Untuk mengukurnya dibutuhkan standar yang memang berfungsi untuk menghitungnya. Pada penelitian ini digunakan standar smart city untuk menentukan tingkat kesejahteraan sebuah kota. Pada standar smart city terdapat beberapa variabel - variabel yang mewakili unsur - unsur yang terdapat dalam sebuah kota.

Pada penelitian ini algoritma fuzzy tipe-2 digunakan untuk mendapatkan klasifikasi smart city yang digunakan sebagai patokan dari tingkat kesejahteraan kota. Algoritma ini digunakan untuk mengolah variabel - variabel dari standar smart city sehingga didapatkan kriteria kesejahteraan kota yang sesuai dengan keadaan kota tersebut.

\section{LANDASAN TEORI}

Setelah algoritma fuzzy tipe-2 ditemukan oleh Zadeh pada [2], terdapat beberapa penelitian yang di dalamnya 
menerapkan algoritma fuzzy tipe-2. Misal, pada [3] dilakukan penerapan algoritma fuzzy tipe-2 general untuk mendapatkan garis latar dan garis tepi dari sebuah citra. Algoritma fuzzy tipe-2 diterapkan dengan cara mendeteksi tingkat gradien warna untuk membedakan warna latar dan warna tepi dari sebuah obyek pada gambar. Hasil yang diperoleh adalah algoritma ini berhasil untuk mendeteksi tepi obyek pada sebuah gambar dengan baik pada gambar dengan noise ataupun tidak dengan 3 format warna berbeda.

Tidak hanya pada citra, algoritma fuzzy tipe-2 juga mampu diterapkan pada perangkat keras. Pada penelitian [4]-[6] dilakukan penerapan algoritma fuzzy tipe-2 pada perangkat keras. Wen, dkk [4], telah menerapkan algoritma fuzzy tipe-2 untuk mengatur sinyal pada pengendali lampu lalu lintas adaptif. Pada [5], penerapan algoritma fuzzy tipe-2 dilakukan pada penentuan jalur robot. Sedangkan pada [6], penerapan dilakukan pada motor servo dc. Penerapan algortima fuzzy tipe-2 pada ketiga penelitian tersebut terbukti mampu menghasilkan keputusan yang baik.

Penelitian [7] berisi penerapan standar smart city menggunakan algoritma fuzzy tipe-1 (fuzzy biasa). Di dalamnya dilakukan pengelompokan kota berdasarkan kriteria smart city menggunakan fuzzy tipe-1. Hasil yang diperoleh yaitu pengelompokan kota berdasarkan standar smart city berhasil dilakukan.

Konsep fuzzy tipe-2 ditemukan pada [2]. Secara umum himpunan fuzzy tipe 2 berbentuk :

$$
\begin{gathered}
\tilde{A}=\{((x, u), \mu \tilde{A}(x, u)) \mid \forall x \in X, \forall u \in \mathrm{J} x \subseteq[0,1], \\
\mu \tilde{A}(x, u) \subseteq[0,1] .
\end{gathered}
$$

Setelah itu ditemukan beberapa cara untuk menerapkan konsep tersebut, yang paling populer adalah fuzzy tipe-2 general dan interval. Pada tipe interval, derajat keanggotaan kedua bernilai 1 atau 0 , sedangkan pada tipe general, derajat keanggotaan kedua bernilai fuzzy. Derajat keanggotaan kedua mengacu pada fungsi keanggotaan tertentu (biasanya segitiga atau trapesium) yang mempunyai nilai pada interval $[0,1]$

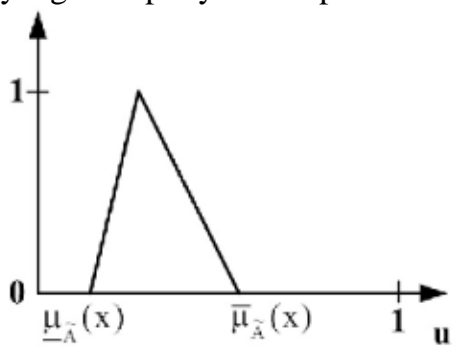

Gambar 1. Derajat keanggotaan kedua himpunan fuzzy tipe-2 general

Ketidakpastian pada himpunan fuzzy tipe-2 dinyatakan dengan wilayah yang dibatasi [3]. oleh karena itu, bagian 2D (x, u) dari $\mu \_\tilde{A}(x, u)$ disebut Footprint Of Uncertainty (FOU) dari $\overline{\tilde{A}}$ dan dinyatakan dengan persamaan berikut :

$\operatorname{FOU}(\tilde{A})=\{(x, u) \in X x[0,1] \mu \tilde{A}(x, u)>0\} . \quad(2)$

FOU dibatasi dengan batas atas(Upper Membership Function) dan batas bawah (Lower Membership Function) yang biasa disebut dengan UMF dan LMF [8]. UMF dan LMF dapat dinyatakan dengan persamaan berikut [9]:

$$
\begin{aligned}
& \overline{\mathrm{X}} \equiv \overline{\mathrm{FOU}}(\tilde{\boldsymbol{A}}) \mid \forall \mathrm{x} \in \mathbf{X} . \\
& \underline{\mathrm{X}} \equiv \underline{\mathrm{FOU}}(\tilde{\boldsymbol{A}}) \mid \forall \mathrm{x} \in \mathbf{X} .
\end{aligned}
$$

Smart City adalah kota berkinerja baik yang dibangun berdasarkan kombinasi langkah cerdas dan kegiatan penentuan nasib sendiri, warga negara yang mandiri dan sadar [10].

Mengacu pada penelitian [7]. Terdapat 6 variabel penentu smart city yaitu :

- Smart Governance, mengacu pada pelayanan kota terhadap masyarakat secara umum.

- Smart Economy, mengacu pada fasilitas yang menunjang ekonomi kota.

- Smart Mobility, mengacu pada fasilitas transportasi kota.

- Smart People, mengacu pada fasilitas peningkatan kualitas pribadi masyarakat.

- Smart Living, mengacu pada fasilitas peningkatan kualitas hidup masyarakat.

- Smart Life/Environment, mengacu pada fasilitas pemberdayaan lingkungan.

Variabel - variabel diatas disebut smart features yang menjadi variabel penentu tingkat sebuah kota terhadap standar smart city.

\section{PERANCANGAN SISTEM}

Implementasi algoritma dilakukan pada platform game PC bernama Malang Urban. Game ini berisi tentang pengelolaan kota oleh pemain untuk mendapatkan nilai tertentu. Penerapan algoritma fuzzy tipe-2 digunakan untuk mencari nilai smart city yang dapat menjadi tolok ukur kesejahteraan kota. Berikut adalah bagian - bagian yang diperlukan untuk penerapan algoritma pada penelitian ini :

\section{A. Smart Features}

Variabel ini merupakan nilai masukan yang diperlukan untuk mendapatkan nilai smart city. Terdapat 6 smart features yang digunakan pada penelitian ini, yaitu :

- Smart Governance

- Smart Economy

- Smart Mobility

- Smart People

- Smart Living

- Smart Environment.

\section{B. Variabel Warga}

Variabel warga merupakan variabel di dalam game yang mewakili nilai atribut dari warga. Setiap variabel akan diolah pada proses di dalam game untuk mendapatkan nilai - nilai smart features. Sebagian nilai variabel - variabel warga bersumber dari nilai yang didapatkan ketika obyek game ditempatkan. Sebagian berasal dari variabel warga yang telah diolah.

\section{Obyek Game}

Obyek di dalam game menghasilkan nilai tertentu yang dapat memberikan nilai tertentu terhadap variabel warga. Ketika sebuah obyek pemerintahan menjangkau 
rumah warga, maka nilai tertentu akan ditambahkan kepada variabel warga sesuai dengan fungsi obyek tersebut. Nilai yang didapat dari obyek game ini berfungsi sebagai sumber nilai yang didapatkan di dalam game. Berikut diagram blok alur didapatkannya nilai dari sebuah smart feature, yaitu smart governance:

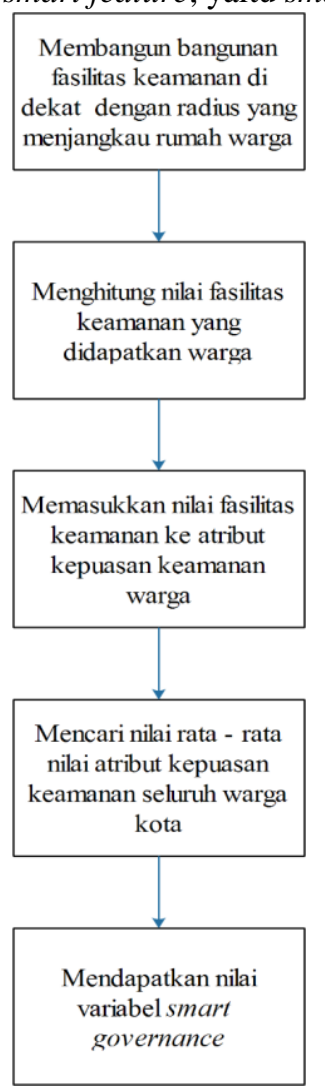

Gambar 2. Diagram blok alur didapatkannya nilai smart governance

\section{Fuzzifikasi}

Fuzzifikasi dilakukan untuk mengubah nilai tegas yang berasal dari nilai smart feature menjadi nilai fuzzy. Nilai fuzzy mewakili besarnya derajat keanggotaan nilai smart feature terhadap anteseden. Pada penelitian ini, terdapat 3 anteseden yaitu :

- not ready, dengan derajat keanggotaan atas berasal dari nilai $(0-70)$ dan derajat keanggotaan bawah berasal dari nilai $(0$ - 60).

- standard, dengan derajat keanggotaan atas berasal dari nilai (45 - 85) dan derajat keanggotaan bawah berasal dari nilai (55 - 75).

- good smart, dengan derajat keanggotaan atas berasal dari nilai $(60-100)$ dan derajat keanggotaan bawah berasal dari nilai $(70$ - 100).

\section{E. Kaidah Fuzzy}

Merujuk pada [7], kaidah yang digunakan untuk mendapatkan nilai smart city adalah sebagai berikut:

Tabel 1. Kaidah fuzzy

\begin{tabular}{llllllll}
\hline No. & SF1 & SF2 & SF3 & SF4 & SF5 & SF6 & SC \\
\hline 1. & G & G & G & G & G & G & G \\
2. & G & G & G & G & G & A & G \\
3. & G & G & G & G & A & G & G \\
4. & G & G & G & A & G & G & G \\
5. & G & G & A & G & G & G & G \\
6. & G & A & G & G & G & G & G
\end{tabular}

\begin{tabular}{|c|c|c|c|c|c|c|c|}
\hline 7. & A & $\mathrm{G}$ & $\mathrm{G}$ & $\mathrm{G}$ & $\mathrm{G}$ & $\mathrm{G}$ & G \\
\hline 8. & $\mathrm{G}$ & $\mathrm{G}$ & $\mathrm{G}$ & $\mathrm{G}$ & A & A & G \\
\hline 9. & $\mathrm{G}$ & $\mathrm{G}$ & $\mathrm{G}$ & A & A & $\mathrm{G}$ & G \\
\hline 10 . & $\mathrm{G}$ & $\mathrm{G}$ & A & A & $\mathrm{G}$ & $\mathrm{G}$ & $\mathrm{G}$ \\
\hline 11. & $\mathrm{G}$ & A & A & $\mathrm{G}$ & $\mathrm{G}$ & $\mathrm{G}$ & G \\
\hline 12. & A & A & $\mathrm{G}$ & $\mathrm{G}$ & $\mathrm{G}$ & $\mathrm{G}$ & G \\
\hline 13. & $\mathrm{G}$ & $\mathrm{G}$ & $\mathrm{G}$ & A & A & A & A \\
\hline 14. & $\mathrm{G}$ & $\mathrm{G}$ & A & A & A & $\mathrm{G}$ & A \\
\hline 15. & $\mathrm{G}$ & A & A & A & $\mathrm{G}$ & $\mathrm{G}$ & A \\
\hline 16. & A & A & A & $\mathrm{G}$ & $\mathrm{G}$ & $\mathrm{G}$ & A \\
\hline 17. & $\mathrm{G}$ & $\mathrm{G}$ & A & A & A & A & B \\
\hline 18 & $\mathrm{G}$ & A & A & A & A & $\mathrm{G}$ & B \\
\hline 19. & $\mathrm{~A}$ & $\mathrm{~A}$ & $\mathrm{~A}$ & $\mathrm{~A}$ & $\mathrm{G}$ & $\mathrm{G}$ & $\mathrm{B}$ \\
\hline
\end{tabular}

Kaidah - kaidah ini digunakan sebagai acuan dalam proses inferensi.

\section{F. Inferensi}

Proses inferensi berfungsi untuk mendapatkan derajat dari sebuah konsekuen. Pada penelitian ini konsekuen mewakili sifat - sifat dari variabel hasil yaitu smart city. Terdapat 3 konsekuen yang digunakan pada penilitian ini, yaitu :

- not ready, dengan derajat keanggotaan atas berasal dari nilai $(0-70)$ dan derajat keanggotaan bawah berasal dari nilai $(0-60)$.

- standard, dengan derajat keanggotaan atas berasal dari nilai $(45$ - 85) dan derajat keanggotaan bawah berasal dari nilai $(55-75)$.

- good smart, dengan derajat keanggotaan atas berasal dari nilai $(60-100)$ dan derajat keanggotaan bawah berasal dari nilai (70 - 100).

\section{G. Reduksi Tipe}

Proses reduksi tipe mengubah himpunan fuzzy tipe-2 menjadi himpunan fuzzy tipe-1. Pada penelitian ini digunakan algoritma Nie - Tan (NT) untuk melakukan proses reduksi tipe. Secara umum algoritma NT berbentuk sebagai berikut :

$$
y_{N T}\left(x^{\prime}\right)=\operatorname{Cog}\left\{\frac{1}{2}\left[\underline{\mu}_{B}\left(y \mid x^{2}\right)+\bar{\mu}_{B}\left(y \mid x^{2}\right)\right]\right\} .
$$

\section{H. Defuzzifikasi}

Proses defuzzifikasi pada algoritma fuzzy tipe-2 biasanya sudah tersambung dengan proses reduksi tipenya. Pada penelitian ini proses defuzzifikasi menggunakan algoritma Nie - Tan yang sudah dipakai pada proses reduksi tipe. Secara umum proses defuzzikasi menggunakan algoritma NT adalah sebagai berikut :

$$
y_{N \tau}\left(x^{r}\right)=\sum_{j=1}^{b} a_{j} y_{N \tau, \alpha_{j}}\left(x^{r}\right) / \sum_{j=1}^{\mathrm{k}} a_{j}
$$

Pada proses ini didapatkan nilai smart city yang digunakan untuk mendapatkan kriteria kesejahteraan kota. Kriteria kesejahteraan kota berdasar pada nilai tegas berikut : 
Tabel 2. Klasifikasi smart city

\begin{tabular}{lll}
\hline \hline No. & Nama Kategori & Interval Nilai \\
\hline 1 & NotReady & $0-50$ \\
2 & Standard & $51-79$ \\
3 & Good Smart & $80-100$ \\
\hline \hline
\end{tabular}

\section{PEMBAHASAN}

\section{A. Uji Coba}

Uji coba dilakukan di dalam game pada skala 1 tahun game.

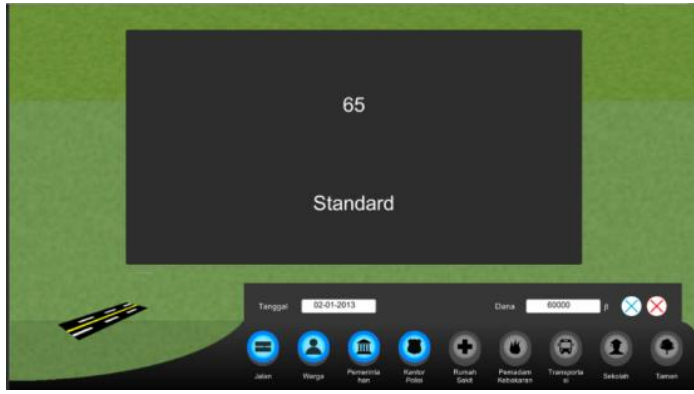

Gambar 3. Hasil nilai smart city dan kategori

Gambar 3. menunjukkan hasil yang didapatkan dari uji coba yang telah dilakukan. Selain nilai diatas, dilakukan percobaan lanjutan dengan nilai sebagai berikut :

Tabel 3. Hasil uji coba

\begin{tabular}{|c|c|c|c|c|c|c|c|c|}
\hline $\begin{array}{l}\mathrm{N} \\
\mathrm{o} .\end{array}$ & $\begin{array}{c}S F \\
1\end{array}$ & $\begin{array}{c}S F \\
2\end{array}$ & $\begin{array}{c}S F \\
3\end{array}$ & $\begin{array}{c}S F \\
4\end{array}$ & $\begin{array}{c}S F \\
5\end{array}$ & $\begin{array}{c}S F \\
6\end{array}$ & $S C$ & $\begin{array}{c}\text { Katego } \\
\text { ri }\end{array}$ \\
\hline 1. & 60 & 51 & 52 & 70 & 73 & 58 & 0 & $\begin{array}{c}\text { Not } \\
\text { Ready }\end{array}$ \\
\hline 2. & 63 & 60 & 78 & 72 & 69 & 53 & 0 & $\begin{array}{l}\text { Not } \\
\text { Ready }\end{array}$ \\
\hline 3. & 52 & 65 & 62 & 74 & 59 & 56 & 0 & $\begin{array}{c}\text { Not } \\
\text { Ready }\end{array}$ \\
\hline 4. & 70 & 37 & 79 & 15 & 54 & 70 & 0 & $\begin{array}{l}\text { Not } \\
\text { Ready }\end{array}$ \\
\hline 5. & 60 & 14 & 46 & 16 & 44 & 60 & 0 & $\begin{array}{c}\text { Not } \\
\text { Ready }\end{array}$ \\
\hline 6. & 17 & 26 & 17 & 80 & 21 & 17 & 0 & $\begin{array}{l}\text { Not } \\
\text { Ready }\end{array}$ \\
\hline 7. & 12 & 15 & 52 & 79 & 76 & 12 & 0 & $\begin{array}{l}\text { Not } \\
\text { Ready }\end{array}$ \\
\hline 8. & 53 & 35 & 61 & 16 & 75 & 53 & 0 & $\begin{array}{l}\text { Not } \\
\text { Ready }\end{array}$ \\
\hline 9. & 57 & 77 & 61 & 71 & 77 & 57 & 0 & $\begin{array}{c}\text { Not } \\
\text { Ready }\end{array}$ \\
\hline 10 & 52 & 65 & 81 & 75 & 92 & 52 & 0 & $\begin{array}{l}\text { Not } \\
\text { Ready }\end{array}$ \\
\hline 11 & 80 & 95 & 59 & 95 & 84 & 80 & $\begin{array}{c}84,4 \\
6\end{array}$ & $\begin{array}{l}\text { Good } \\
\text { Smart }\end{array}$ \\
\hline 12 & 95 & 58 & 71 & 59 & $\begin{array}{c}10 \\
0\end{array}$ & 95 & $\begin{array}{c}65,0 \\
0\end{array}$ & $\begin{array}{l}\text { Standa } \\
\quad r d\end{array}$ \\
\hline 13 & 50 & 78 & 62 & 73 & 96 & 50 & 0 & $\begin{array}{c}\text { Not } \\
\text { Ready }\end{array}$ \\
\hline 14 & 80 & 98 & 90 & 85 & 76 & 80 & $\begin{array}{c}85,0 \\
2\end{array}$ & $\begin{array}{l}\text { Good } \\
\text { Smart }\end{array}$ \\
\hline 15 & 96 & 71 & 90 & 83 & 83 & 96 & $\begin{array}{c}84,4 \\
6\end{array}$ & $\begin{array}{l}\text { Good } \\
\text { Smart }\end{array}$ \\
\hline
\end{tabular}

SF1 = Smart Governance, SF2 = Smart Economy, SF3 = Smart Mobility, SF4 = Smart People, SF5 = Smart Life, SF5 = Smart Environment, $\mathrm{SC}=$ Smart City
Nilai - nilai dari smart features pada Tabel 3. didapatkan dari nilai yang didapatkan dari 15 percobaan pada game. Nilai smart city didapatkan dengan pengolahan algoritma fuzzy tipe-2 yang telah diimplementasikan di dalam game.

\section{B. Analisa}

Dari percobaan diatas didapatkan hasil nilai Smart City dengan kriteria not ready sebesar $73,33 \%$, standard sebesar 6,67\% dan good smart Sebesar $20 \%$. Banyanknya nilai not ready dikarenakan adanya nilai nilai yang tidak termasuk pada anteseden standard dan good smart yang dijadikan sebagai dasar pada pembuatan kaidah. Pada Tabel 1. tidak ada nilai masukan dengan anteseden not ready sehingga ketika nilai dari salah satu smart features lebih dekat kepada anteseden not ready maka akan menghasilkan kategori smart city bernilai not ready.

\section{KESIMPULAN}

Dari hasil uji coba dan pembahasan maka dapat ditarik kesimpulan bahwa algoritma fuzzy tipe-2 general mampu mendapatkan hasil tingkat kesejahteraan kota berdasarkan standar smart city. Hasil yang didapatkan sesuai dengan kaidah yang telah ditetapkan pada penelitian ini. Dari percobaan - percobaan yang dilakukan pada penelitian ini didapatkan hasil kriteria kota dengan nilai kriteria not ready sebesar $73,33 \%$, standard sebesar 6,67\% dan good smart Sebesar $20 \%$.

\section{REFERENSI}

[1] U. Solid, "Apa itu Tata Kota?,” 25-Feb-2015. [Daring]. Tersedia pada: http://ciricara.com/2015/02/25/apa-itu-tata-kota/. [Diakses: 08-Des-2018].

[2] L. A. Zadeh, "The Concept of a Linguistic Variable and its Application to Approximate Reasoning-I," Inf. Sci., vol. 8, no. 3, hlm. 199-249, 1975, doi: 10.1016/0020-0255(75)90036-5.

[3] C. I. Gonzalez, P. Melin, dan O. Castillo, "Edge Detection Method Based on General Type-2 Fuzzy Logic Applied to Color Images," Information, vol. 8, no. 104, hlm. 1-15, 2017, doi: https://doi.org/10.3390/info8030104.

[4] C. Wen, Z. Hui, dan L. Yuling, "Intelligent traffic signal controller based on type-2 fuzzy logic and NSGAII," J. Intell. Fuzzy Syst, vol. 29, no. 6, hlm. 2611 - 2618, doi: https://doi.org/10.3233/IFS-151964.

[5] T. Kumbasar dan H. Hagras, "A Type-2 Fuzzy Cascade Control Architecture for Mobile Robots," IEEE Int. Conf. Syst. Man Cybern., hlm. $3226 \quad-\quad 3231, \quad$ doi: https://doi.org/10.1109/SMC.2013.550.

[6] M. Z. Al - Faiz dan M. S. Saleh, "Design and Implementation of Type 2 Fuzzy Logic Controllers for The Position Control of a DC Servo Motor," Diyala J. Eng. Sci., vol. 07, no. 03, hlm. 120130, 2014

[7] M. I. Perangin-angin, Khairul, dan P. U. S. Andysah, "Fuzzy Logic Concept in Technology, Society, and Economy Areas in Predicting Smart City," Int. J. Appl. Eng. Res., vol. 2, no. 12, hlm. 176-181, Des 2016.

[8] D. Wu, "Approaches for Reducing the Computational Cost of Interval Type-2 Fuzzy Logic Systems: Overview and Comparisons," IEEE Trans. Fuzzy Syst., vol. 21, no. 1, hlm. 8099, Feb 2013, doi: 10.1109/TFUZZ.2012.2201728.

[9] J. M. Mendel, R. I. B. John, dan F. Liu, "Interval Type-2 Fuzzy Logic Systems Made Simple,” IEEE Trans. Fuzzy Syst., vol. 14, no. 6, hlm. 808-821, 2006, doi: https://doi.org/10.1109/TFUZZ.2006.879986.

[10] R. Giffinger, C. Fertner, H. Kramar, R. Kalasek, N. PichlerMilanović, dan E. Meijers, "Smart cities Ranking of European medium-sized cities." 2007. 